\title{
Effects of serotonergic drugs in rats trained to discriminate clozapine from haloperidol
}

\author{
JENNY L. WILEY and JOSEPH H. PORTER \\ Virginia Commonwealth University, Richmond, Virginia
}

\begin{abstract}
Because of the low discriminability of most neuroleptics, their use as stimuli in two-lever drug discrimination procedures has not been widespread. Several recent reports have demonstrated that the atypical neuroleptic clozapine (CLZ) has stronger cue properties than typical neuroleptics such as haloperidol (HAL). Most of these studies have tested animals trained to discriminate CLZ from vehicle. The present study examined the effects of CLZ, HAL, and three centrally acting serotonergic drugs (ritanserin, MDL 72222, and buspirone) in a drug-drug discrimination procedure with rats trained to discriminate CLZ $(5.0 \mathrm{mg} / \mathrm{kg})$ from HAL $(0.03 \mathrm{mg} / \mathrm{kg})$. Rats responded predominantly on the CLZ lever during substitution tests with CLZ. Substitution tests with the other four drugs produced $50 \%$ or less responding on the CLZ lever. These results are consistent with those of a previous study in which rats were trained to discriminate CLZ from vehicle (Wiley \& Porter, 1992) and suggest that the CLZ cue is not mediated by blockade of dopamine D2 receptors, antagonism at 5-HT2 or 5-HT3 receptors, or agonistic activity at 5-HT1A receptors. Potential clinical implications of these results are discussed.
\end{abstract}

Typical neuroleptics such as haloperidol are only weakly discriminable in two-lever drug discrimination procedures (Overton, 1971); in contrast, the atypical neuroleptic clozapine has been shown to have moderate to strong discriminative stimulus effects (Browne \& Koe, 1982; Goas \& Boston, 1978). On the basis of this difference in degree of discriminability, it might be expected that clozapine and haloperidol would not cross-generalize in these procedures. Indeed, in earlier studies, we reported that haloperidol does not substitute for clozapine in rats trained to discriminate clozapine from vehicle (Wiley \& Porter, 1992; Villanueva, Arezo, Rosecrans, \& Porter, 1990 ). Because of the difficulty in training rats to discriminate haloperidol from vehicle, clozapine has not been tested in haloperidol-trained rats.

Since clozapine and haloperidol do not produce similar interoceptive cues, it should be possible to train rats to discriminate clozapine from haloperidol. In the present study, we tested clozapine and haloperidol in this type of drug-drug discrimination procedure. Following determination of dose-effect curves with the training drugs, centrally acting serotonergic drugs, selective for 5-HT1A (buspirone), 5-HT2 (ritanserin), and 5-HT3 (1-alphaH,3alpha,5-alphaH-tropan-3yl-3,5-dichlorobenzoate [MDL 72222]) sites, were tested in substitution tests. Previously, we found that these drugs did not substitute for clozapine in clozapine-trained rats (Wiley \& Porter, 1992); how-

The authors express appreciation to Robert Balster for his gift of MDL 72222 and to Daniel Kimbrough for his gift of ritanserin. J. L. Wiley is now at the Department of Pharmacology/Toxicology, Medical College of Virginia, Richmond, VA 23298-0613. Correspondence should be addressed to J. H. Porter, Department of Psychology, Virginia Commonwealth University, Richmond, VA 23284-2018. ever, a drug-drug discrimination procedure with clozapine and haloperidol (a D2 dopamine blocker) might be expected to eliminate dopamine antagonism as the basis of clozapine lever selection (e.g., see Overton, 1982) and could magnify the serotonergic basis of the clozapine stimulus.

\section{METHOD}

\section{Subjects}

Fifteen naive adult male Sprague-Dawley rats (375-475 g), obtained from Dominion Breeders (Dublin, VA), were reduced to $85 \%$ of their free-feeding body weight by restriction of food intake. They were maintained at this weight for the duration of the experiment and received their daily food ration (10-20 g of Agway Prolab MHR 3000 Rodent Chow) following experimental sessions. The animals were individually housed in wire cages in a temperature-controlled $\left(22^{\circ} \mathrm{C}\right)$ environment with a 12:12-h light:dark cycle (lights on at 6 a.m.). They had free access to water in their home cages.

\section{Apparatus}

Three standard operant chambers (BRS/LVE, Laurel, MD, Model SEC-002), housed in sound-attenuated cubicles, were used. Each chamber contained two levers, mounted on either side of the intelligence panel $5 \mathrm{~cm}$ above the grid floor. A pellet dispenser (BRS/LVE, PDC/PPD Series) delivered $45 \mathrm{mg}$ BIO SERV (Frenchtown, NJ) food pellets to a food cup located between the two levers in the center of the intelligence panel $1.6 \mathrm{~cm}$ above the floor. Fan motors provided ventilation and masking noise for each chamber. A 7-W houselight was located on the intelligence panel $22.4 \mathrm{~cm}$ above the food cup. Solid-state programming equipment in an adjacent room was used to control the operant schedule and to record data.

\section{Drugs}

Haloperidol (HAL), clozapine (CLZ), and ritanserin (RIT) were prepared in a vehicle solution of $85 \%$ lactic acid (5-10 drops) and distilled water. MDL 72222 was prepared in a solution of $0.9 \%$ saline and lactic acid (5-10 drops). Buspirone $\mathrm{HCl}$ (BSP) was dissolved in $0.9 \%$ saline. All doses of CLZ, HAL, and BSP were administered intraperitoneally (i.p.) at a volume of $1 \mathrm{ml} / \mathrm{kg}$ of body weight. RIT (15 and $20 \mathrm{mg} / \mathrm{kg}$ ) 
and MDL 72222 (6 and $9 \mathrm{mg} / \mathrm{kg}$ ) were administered i.p. at a volume of $2 \mathrm{ml} / \mathrm{kg}$ of body weight. Doses of BSP refer to the salt; doses of all other drugs refer to the free base. Presession injection interval was $1 \mathrm{~h}$ for CLZ, $45 \mathrm{~min}$ for HAL, $30 \mathrm{~min}$ for RIT and MDL 72222, and $15 \mathrm{~min}$ for BSP.

\section{Procedure}

Training procedures similar to those previously described (Wiley \& Porter, 1992) were used. Briefly, rats were trained to press one lever following administration of CLZ $(5.0 \mathrm{mg} / \mathrm{kg}$, i.p.) and to press a second lever following administration of $\operatorname{HAL}(0.03 \mathrm{mg} / \mathrm{kg}$, i.p. $)$ in a two-lever drug discrimination procedure. During each day of discrimination training, only one of the two levers present in the operant chamber delivered reinforcement according to a fixed ratio (FR) 30 schedule. The position of the reinforced (correct) lever was determined by the type of injection the rat received on a given day. Each response on the incorrect lever reset the ratio requirement on the correct lever. The daily injection for each rat was administered in a double alternation sequence of $5.0 \mathrm{mg} / \mathrm{kg} \mathrm{CLZ}$ and $0.03 \mathrm{mg} / \mathrm{kg}$ HAL (i.e., CCHHCCHH). Throughout the entire procedure, training and testing occurred during daily $15-\mathrm{min}$ sessions Monday through Friday.

Following testing for acquisition of the discriminative cue, stimulus generalization tests with CLZ (1.25-20.0 mg/kg), HAL (0.015-0.10 $\mathrm{mg} / \mathrm{kg})$, RIT $(2.5-20.0 \mathrm{mg} / \mathrm{kg})$, MDL 72222 (0.1-9.0 mg/kg), BSP $(0.5-2.0 \mathrm{mg} / \mathrm{kg})$, and their vehicles were conducted. Tests typically $\alpha c-$ curred on Tuesdays and Fridays. On test days, responses on either lever delivered reinforcement according to a FR30 schedule. In order to be tested, a rat must have met three criteria on the previous day: (1) the first completed FR30 must have been made on the correct lever; (2) percent of correct-lever responding during the 15-min session must have equaled or exceeded $85 \%$; and (3) response rate must have been greater than or equal to 30 responses per minute. The rats that developed a preference for a specific lever position or whose responding or discriminative control deteriorated (as indicated by consistent failure to meet control criteria) were dropped from the study.

\section{Data Analysis}

For each test session, percentage of CLZ lever responding (i.e., number of responses on the CLZ lever divided by total number of responses and converted to a percentage) and response rate (i.e., responses per minute) were calculated. A repeated measures analysis of variance (ANOVA) comparing response rate on test days was performed separately for each test drug. Duncan post hoc tests $(\alpha=.05)$ were used to specify differences from the vehicle dose revealed by significant ANOVAs (Brunning \& Kintz, 1977). The ED50 for CLZ (with 95\% confidence intervals) was calculated with the least squares method of linear regression on the linear part of the dose-effect curve (Goldstein, 1964) for percentage of CLZ-lever responding (ordinate) plotted against $\log 10$ transformation of the dose (abscissa). (Data for the rats that had fewer than five responses per minute were excluded from the dose-effect curve for percentage of CLZ-lever responding.)

\section{RESULTS}

Seven of the original 15 rats successfully completed acquisition testing and were tested for stimulus generalization with CLZ. In these rats, CLZ substituted for the training dose $(5.0 \mathrm{mg} / \mathrm{kg})$ in a dose-dependent manner $(\mathrm{ED} 50=1.6 \mathrm{mg} / \mathrm{kg}, 95 \%$ confidence interval $=0.8-2.9$ $\mathrm{mg} / \mathrm{kg}$; Figure 1, upper panel). HAL $(n=5), \operatorname{RIT}(n=$ $5)$, MDL $72222(n=3)$, and BSP $(n=2)$ failed to substitute for CLZ, producing $50 \%$ or less CLZ-lever responding at all doses tested (Figure 1, upper panel). Compared with vehicle controls, response rates were reduced by the higher doses of each drug (Figure 1, lower panel).
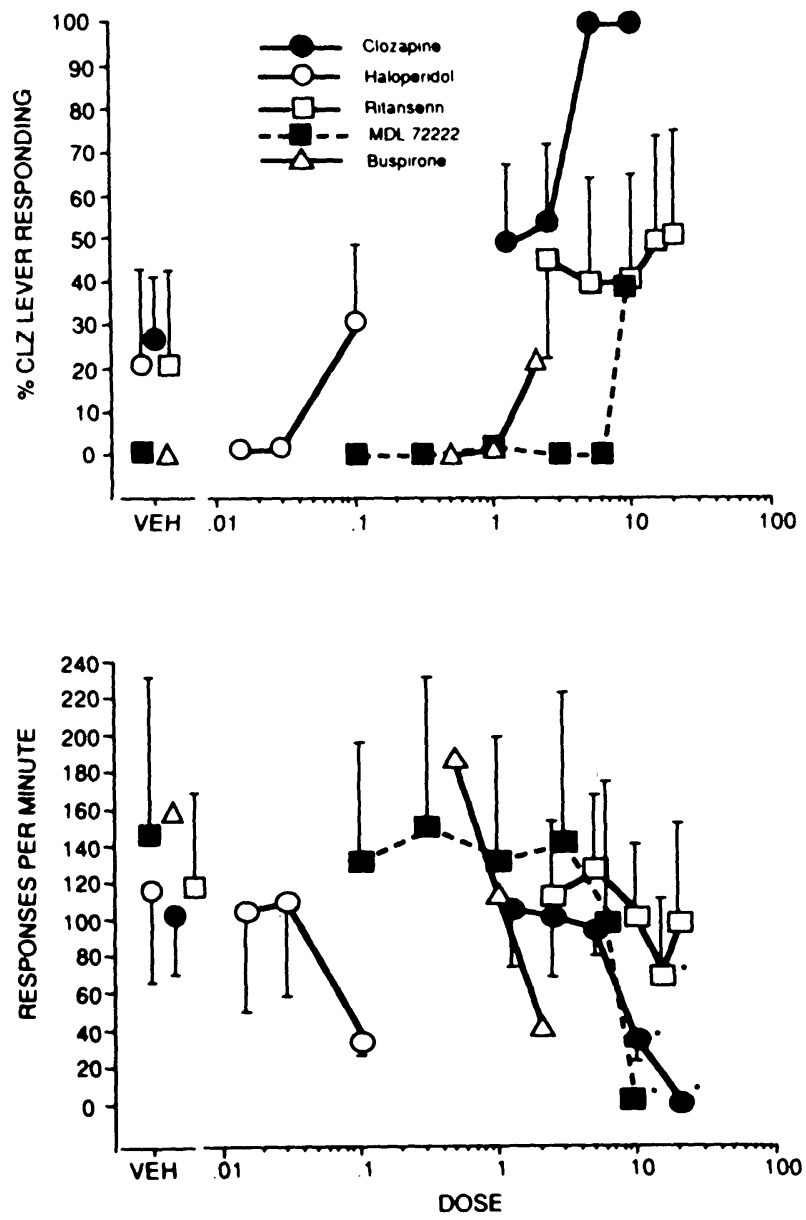

Figure 1. Mean percentage of clozapine-lever responding ( $\pm S E M)$ (upper panel) and mean response rate $( \pm S E M)$ (lower panel) as a function of drug dose in rats trained to discriminate $5.0 \mathrm{mg} / \mathrm{kg}$ clozapine from $0.03 \mathrm{mg} / \mathrm{kg}$ haloperidol.

\section{DISCUSSION}

Previous reports have shown that rats can be trained to discriminate CLZ from vehicle and CLZ from chlorpromazine in two-lever drug discrimination procedures (Goas \& Boston, 1978; Wiley \& Porter, 1992). Nearly half of the rats that began training in the present study successfully completed acquisition testing. These results indicate that CLZ can also be discriminated from HAL, albeit with more difficulty than in a drug-versus-vehicle paradigm (Wiley \& Porter, 1992).

When tested in substitution tests with the training drugs, CLZ-versus HAL-trained rats responded predominantly on the CLZ lever following CLZ administration and on the HAL lever after HAL injection. CLZ substitution for the $5.0 \mathrm{mg} / \mathrm{kg}$ training dose was dose dependent; HAL substitution for the $0.03 \mathrm{mg} / \mathrm{kg}$ training dose was not dose dependent. Whereas the two lowest doses of HAL produced responding almost exclusively on the HAL lever, the highest dose of HAL $(0.1 \mathrm{mg} / \mathrm{kg})$ decreased percentage of HAL-lever responding. This decrease was accompanied by a decrease in overall response rate. At all doses, HAL produced less-than-chance levels of CLZ-lever responding. The fact that CLZ produced dose-dependent generalization to the CLZ cue, whereas HAL generalization to the HAL cue was not dose dependent, suggests that the CLZ cue was more salient than the HAL cue. It is also possible 
that rats learned to detect the CLZ cue, but not the HAL cue; that is, rather than having distinctive cue properties of its own, HAL may have been treated as "not CLZ" in this forced-choice procedure. The fact that responding following injection with vehicle produced primarily $\mathrm{HAL}$ lever responding lends support to this idea.

Interestingly, as stimulus generalization testing progressed, stimulus control deteriorated in some subjects (who were subsequently dropped from the study). This problem was less severe or absent in rats trained in a CLZ-versus-vehicle procedure performed in this laboratory (Wiley \& Porter, 1992). It is possible that dopamine-mediated motor or anhedonic effects (e.g., Wiley \& Porter, 1990; Wise, 1982) resulting from chronic dosing with the dopamine antagonist HAL interfered with maintenance of discriminative control for some rats in the present study.

RIT (5-HT2 antagonist), MDL 72222 (5-HT3 antagonist), and BSP (5-HT1A agonist) were tested in the remaining rats and produced vehiclelike responding on the HAL-associated lever at all doses tested. Thus, drug-drug discrimination with CLZ and HAL did not reveal a serotonergic component of CLZ's discriminative stimulus effects. These results are consistent with those of our previous study (Wiley \& Porter, 1992) and suggest that the CLZ cue is not mediated by antagonism at 5-HT2 or 5-HT3 receptors or by agonistic activity at 5-HT1A receptors.

The results of the present study have at least two potential implications for the use of CLZ in treating schizophrenia. First, clinical and preclinical research indicates that the therapeutic activity of antipsychotic drugs is probably mediated by antagonism at dopamine receptors (Niemegeers \& Leysen, 1982), antagonism at 5-HT2 or 5-HT3 receptors (Bleich, Brown, Kahn, \& Van Praag, 1988; Costall, Domeney, Naylor, \& Tyers, 1987; Costall, Naylor, \& Tyers, 1990; Hagan, Jones, Jordan, \& Tyers, 1990; Janssen et al., 1988), or agonistic activity at 5-HT1A receptors (Ahlenius, 1989). Results of the present study and of previous research suggest that the CLZ cue is not mediated by action at any of these receptors; hence, CLZ's discriminative stimulus effects may not be correlated with its antipsychotic effects. It is possible that CLZ's cue properties may be related to its side effects. Nielsen (1988) reports that drugs that block muscarinic receptors substitute for CLZ in CLZ-trained rats. CLZ's low liability for production of extrapyramidal motor effects in humans may also be mediated by its anticholinergic properties (Anden \& Stock. 1973; Bunney \& Aghajanian, 1975; Creese \& Snyder, 1978) Thus, in conjunction with current screening tests for neuroleptic action, CLZ discrimination procedures may be useful in development of antipsychotics that lack extrapyramidal motor effects.

Second, the discriminative stimulus effects of psychoactive drugs in animals represent a model for the subjective effects of these drugs in humans (Balster, 1990). The subjective effects of typical neuroleptics such as HAL may be related to problems with patient compliance in maintenance therapy with these drugs. The results of CLZ discrimination studies suggest that CLZ may not share these troublesome subjective effects.

In summary, the results of the present study support previous research suggesting that CLZ and HAL do not share discriminative stimulus effects. Although drug discrimination studies with CLZ-trained animals have not yet revealed the neural basis for CLZ's discriminative stimulus effects, the fact that CLZ and HAL can be discriminated from each other has potential clinical implications.

\section{REFERENCES}

Ahlenius, S. (1989). Antipsychotic-like properties of the 5-HT1A agonist 8-OH-DPAT in the rat. Pharmacology \& Toxicology, 64, 3-5. ANden, N. E., \& STock, G. (1973). Effect of clozapine on the turnover of dopamine in the corpus striatum and in the limbic system. Journal of Pharmacy \& Pharmacology, 25, 346-348.

Balster, R. L. (1990). Perception of drug effects. In M. A. Berkley \& W. C. Stebbins (Eds.), Comparative perception (Vol. 1, pp. 127154). New York: Wiley.

Bleich, A., Brown, S. L., Kahn, R., \& van PraAg, H. M. (1988).
The role of serotonin in schizophrenia. Schizophrenia Bulletin, 14, 297-315.

Browne, R. G., \& KoE, B. K. (1982). Clozapine and agents with similar behavioral and biochemical properties. In F. C. Colpaert \& J. L. Stangen (Eds.), Drug discrimination: Applications in CNS pharmacology (pp. 241-254). New York: Elsevier.

BRUNNING, J. L., \& KinTZ, B. L. (1977). Computational handbook of statistics. Glenview, IL: Scott, Foresman.

Bunney, B. S., \& Aghajanian, G. K. (1975). Antipsychotic drugs and central dopaminergic neurons: A model for predicting therapeutic efficacy and incidence of extrapyramidal side effects. In A. Sudilovsky, S. Gershon, \& B. Beer (Eds.), Predictability in psychopharmacology: Preclinical and clinical correlations (pp. 225-245). New York: Raven.

Costall, B., Domeney, A. M., Naylor, R. J., \& Tyers, M. B. (1987). Effects of the 5-HT3 receptor antagonist, GR38032F, on raised dopaminergic activity in the mesolimbic system of the rat and marmoset brain. British Journal of Pharmacology, 92, 881-894.

Costall, B., NAYlor, R. J., \& TYers, M. B. (1990). The psychopharmacology of 5-HT3 receptors. Pharmacology Therapeutics, 47, 181-202.

Creese, I., \& SNyder, S. H. (1978). Behavioral and biochemical properties of the dopamine receptor. In M. A. Lipton, A. DiMascio, \& K. F. Killam (Eds.), Psychopharmacology: A generation of progress (pp. 377-388). New York: Raven.

Goas, J. A., \& Boston, J. E. (1978). Discriminative stimulus properties of clozapine and chlorpromazine. Pharmacology, Biochemistry \& Behavior, 8, 235-241.

Goldstein, A. (1964). Biostatistics: An introductory text. New York: Macmillan.

Hagan, R. M., Jones, B. J., Jordan, C. C., \& Tyers, M. B. (1990). Effect of 5-HT3 receptor antagonists on responses to selective activation of mesolimbic dopaminergic pathways in the rat. British Journal of Pharmacology, 99, 227-232.

Janssen, P. A. J., Niemegeers, C. J. E., Awouters, F., SchelleKens, K. H. L., Megens, A. A. H. P., \& Meert, T. F. (1988). Pharmacology of risperidone (R 64 766), a new antipsychotic with serotonin-S2 and dopamine-D2 antagonistic properties. Journal of Pharmacology \& Experimental Therapeutics, 244, 685-693.

NIELSEN, E. B. (1988). Cholinergic mediation of the discriminative stimulus properties of clozapine. Psychopharmacology (Berlin), 94, 115-118.

Niemegeers, C. J. E., \& Leysen, J. E. (1982). The pharmacological and biochemical basis of neuroleptic treatment in schizophrenia. Pharmaceutisch Weekblad, Scientific Edition, 4, 71-78.

Overton, D. A. (1971). Discriminative control of behavior by drug states. In T. Thompson \& R. Pickens (Eds.), Stimulus properties of drugs (pp. 87-110). New York: Meredith.

OVERTON, D. A. (1982). Multiple drug training as a method for increasing the specificity of the drug discrimination procedure. Journal of Pharmacology \& Experimental Therapeutics, 221, 166-172.

Villanueva, H. F., Arezo, S., Rosecrans, J. A., \& Porter, J. H. (1990). Discriminative stimulus properties of clozapine. Society for Neuroscience Abstracts, 16, 248.

Wiley, J. L., \& PORTER, J. H. (1990). Differential effects of haloperidol and clozapine on the reinforcing efficacy of food reward in an alleyway reacquisition paradigm. Pharmacology, Biochemistry \& Behavior, 36, 569-573.

Wiley, J. L., \& PORTER, J. H. (1992). Serotonergic drugs do not substitute for clozapine in clozapine-trained rats in a two-lever drug discrimination procedure. Pharmacology, Biochemistry \& Behavior, 43, 961-965.

WISE, R. A. (1982). Neuroleptics and operant behavior: The anhedonia hypothesis. Behavioral \& Brain Sciences, 5, 39-87.

(Manuscript received September 5, 1992.) 